\title{
Diagnostic Significance of Antibodies to the Epstein-Barr Virus-Specific Membrane Antigen gp250
}

Methods for the demonstration of antibodies to the membrane antigen of Epstein-Barr virus (EBV) and for EBVneutralizing antibodies have been described by different authors [1-3]. Because of the complexities of these assays and because they are difficult to perform and to read, however, they have not been widely used for routine diagnostic purposes. Therefore, only limited data are available about antibodies to EBV membrane antigens or about neutralizing antibodies in EBV-infected individuals. The present study was undertaken in order to find out the frequency of antibodies to the EBV membrane antigen, the timing of their appearance, and their possible diagnostic significance. We focused our interest on gp250 - this member of the membrane-antigen complex mediates the binding of the virus to the target cell and induces neutralizing antibodies [4]. In addition, this protein (as well as the antigenically closely related gp350 [4]) is a candidate for a possible EBV subunit vaccine [5]. Furthermore, it is expressed on induced EBV-producer cells and can be easily demonstrated after radioiodination of cell-surface proteins [6]. For the demonstration of antibodies against gp250, we used a radioimmunoprecipitation technique in combination with SDS-PAGE and autoradiography, a method that is very sensitive and is highly specific.

\section{Materials and Methods}

Radioiodination and solubilization of cell-surface proteins. The EBV-producing, MA-positive cell line P3HR-1 and the EBV-negative line $\mathrm{BJ} A B$ were cultured as previously described [7]. For induction of EBV antigens, P3HR1 cultures were treated with $40 \mu \mathrm{g}$ of phorbol- 12 myristate13 acetate/ml immediately after subculture. Cells were harvested for surface labeling three days later.

Lactoperoxidase-catalyzed iodination of cell-surface protein was performed as described earlier [8]. Iodinated cells were suspended in PBS at a concentration of $2 \times$ $10^{7}$ cells $/ \mathrm{ml}$ and were mixed with an equal volume of $1 \%$ Nonidet P-40 (NP-40) in PBS supplemented with Trasylol (Bayer, Leverkusen, Federal Republic of Germany; final concentration, 200 kallikrein inhibitor units $/ \mathrm{ml}$ ) and phenylmethane sulfonyl fluoride (E. Merck, Darmstadt, FRG; final concentration, $2 \mathrm{mmol}$ ). After incubation for $30 \mathrm{~min}$ on ice, the cells were centrifuged at $2,000 \mathrm{~g}$ for 30

Received for publication August 17, 1984, and in revised form December 26, 1984.

We thank Professor Deinhardt for his support and interest and Gabriele Deby and Christine Schäfer for technical assistance.

Please address requests for reprints to Dr. W. Jilg, Max von Pettenkofer Institute, Pettenkoferstrasse 9a, D-8000 München 2, Federal Republic of Germany. min and the supernatant was applied to a Sephadex G-25 column. The first radioactive peak containing the labeled membrane protein was used for the subsequent steps.

Immunoprecipitation. The labeled NP-40 extracts were first precleared with a rabbit antiserum to human peripheral blood lymphocytes (PBLs) in order to remove most of the lymphocyte-specific proteins and to also remove proteins that bind nonspecifically to immobilized protein $\mathrm{A}$. Protein A-Sepharose CL-4B (Pharmacia, Uppsala, Sweden) was incubated with an equal volume of antiserum to PBLs for $3 \mathrm{hr}$ and was washed three times with $0.5 \% \mathrm{NP}-40$ in PBS. We mixed $0.5 \mathrm{ml}$ of the coated beads with $3.5 \mathrm{ml}$ of NP-40 extract prepared from $8 \times 10^{6}$ of surface-labeled cells and gently rotated the mixture for 3 $\mathrm{hr}$ at room temperature. The beads were removed and the supernatant was incubated again for $3 \mathrm{hr}$ with $0.5 \mathrm{ml}$ of beads coated with antiserum to PBLs as above. The precleared extract was diluted to $5 \mathrm{ml}$ and was either immediately used for immunoprecipitation or stored frozen at $-20 \mathrm{C}$. We then mixed $125 \mu \mathrm{l}$ of this extract with 10 $\mu l$ of the serum to be tested and incubated the mixture overnight in the cold. Immune complexes were isolated by adding $100 \mu \mathrm{l}$ of a $20 \%(\mathrm{vol} / \mathrm{vol})$ Protein A-Sepharose suspension in $0.5 \%$ NP-40 in PBS. The mixture was rotated for $3 \mathrm{hr}$ at room temperature, then the beads were washed twice with $0.5 \%$ NP-40 in PBS, transferred to new tubes, washed another two times with PBS, and washed once more with distilled water. The washed beads were suspended in electrophoresis-sample buffer $(50 \mathrm{mM}$ Tris- $\mathrm{HCl}$ [pH 7.0], 2\% SDS, 5\% 2-mercaptoethanol, and 3\% sucrose) and heated to $100 \mathrm{C}$ for $5 \mathrm{~min}$; the supernatant was used for electrophoresis.

SDS-PAGE. SDS-PAGE was performed exactly as described by Bayliss and Wolf [7]. For autoradiography of the dried gel, a Kodak X-omat S film (Rochester, NY) was used in combination with an intensifying screen.

$E B V$ serology. Titers of $\operatorname{IgG}$ and IgM antibody to viral capsid antigen (VCA), IgG antibody to early antigen (EA), and antibody to Epstein-Barr nuclear antigen (EBNA) were determined by indirect immunofluorescence methods [9].

Patient's sera. The sera used in this study came from patients of different clinics and general practitioners, mainly in Munich, and were provided by Professor F. Deinhardt (Max von Pettenkofer Institute, Munich).

\section{Results}

Immunoprecipitation of gp250. Gp250 was immunoprecipitated from ${ }^{125}$ I-labeled membrane proteins of P3HR-1 cells by a serum pooled from patients with nasopharyngeal carcinoma who are known to have high titers of antibodies to membrane antigen. Control precipi- 
tates with this serum from extracts of BJAB cells were negative as were precipitates from P3HR-1 extracts with seven different EBV-negative sera (figure 1, lanes A-C). As nearly all sera precipitated a number of cellular proteins, labeled P3HR-1 extracts were precleared by using a rabbit antiserum to human PBLs. This procedure reduced the backgrund activity considerably; only a few faint, unspecific bands were seen in addition to the EBV protein gp250 and traces of EBV proteins gp 350 and p80 (figure 1, lanes D and E). The sensitivity of the method was evaluated by immunoprecipitation of gp 250 with serial dilutions of the

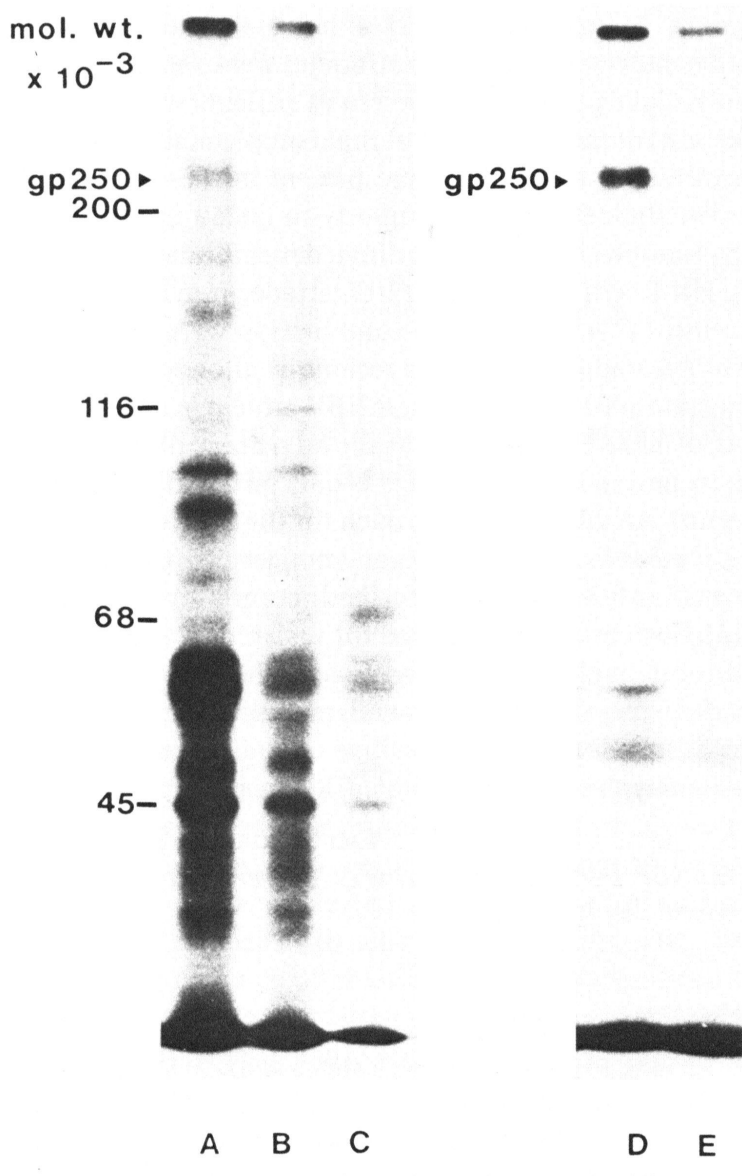

Figure 1. Immunoprecipitation of EBV-specific membrane antigen gp250. Lane A: extract of surface-labeled EBV-producer cells (P3HR-1) immunoprecipitated with a serum that was positive for antibody to membrane antigen. Lane B: control precipitate from labeled EBVnegative cells (BJAB) with serum that was positive for antibody to membrane antigen. Lane $C$ : same as in A, but precipitated with serum that was negative for EBV. Lanes $D$ and $E$ : immunoprecipitations from precleared P3HR-1 extract with serum that was positive for antibody to membrane antigen $(D)$ and that was negative for antibody to $\operatorname{EBV}(E)$. above mentioned serum pool. Starting with $10 \mu \mathrm{l}$ of undiluted serum, gp250 was still detectable at a dilution of $1: 64$.

Determination of antibodies to gp250 in patient's sera. One hundred twenty-one sera from 84 individuals who were positive for EBV were tested for the presence of antibodies to gp250. In addition, all sera were examined for IgG antibodies to VCA and to EBNA and most of them were also examined for IgM antibodies to VCA and to EA.

Thirty sera were drawn from patients with infectious mononucleosis. Twenty-six showed the typical serological pattern of acute infection with EBV: they were positive for IgG antibody to VCA and IgM antibody to VCA and negative for antibody to EBNA. Antibodies to gp250 were lacking in $24(92.3 \%)$ of these sera; in the remaining two (7.7\%), only traces of antibodies to gp250 were found. Four patients with the clinical diagnosis of infectious mononucleosis showed serological signs of the convalescent phase. Two of the patients had sera that were negative for IgM antibody to VCA and had trace amounts of antibody to EBNA. Antibody to gp250 was negative in one serum sample and weakly positive in the other. The other two individuals were positive for IgG and IgM antibodies to VCA, as well as positive for antibody to EBNA. One of these two lacked antibody to gp250 and only trace amounts were found in the other.

Five individuals with acute infection with EBV were followed up for a longer period of time. In two of them, antibody to gp250 appeared four and five weeks after the onset of infectious mononucleosis, whereas two others were still negative for antibody 12 and 14 weeks later (antibodies to EBNA were present at this time). A 14-year-old girl with clinical symptoms of persistent, active infection with EBV such as lymphadenitis colli, recurrent low grade fever, and headaches, did not develop antibody to gp250 or antibody to EBNA during an observation period of 18 months.

In 40 persons, a past infection with EBV was diagnosed on the basis of the presence of antibody to VCA and antibody to EBNA. In addition, IgM antibody to VCA was tested for in 13 sera with negative results in all of them. Thirty-four $(85 \%)$ of these individuals were clearly positive for antibody to gp 250 ; one $(2.5 \%)$ was weakly positive. Five $(12.5 \%)$ persons lacked antibodies to gp250 but did show antibodies to VCA as well as to EBNA. Two of these persons had had serologically proven, acute infectious mononucleosis 10 and 12 weeks before; the other three (a 62-year-old woman and a 27-year-old woman with her eight-month-old son) had no history of clinically apparent infection with EBV. The 62-year-old woman was hospitalized because of indigestion, hepatomegaly, and leukopenia. No cause was found for these symptoms; a bone marrow aspirate showed reactive plasmocytosis. The 27-year-old woman was apparently healthy. Her son, however, had congenital hepatomegaly and very slight mal- 
Table 1. Antibodies to gp250 in sera from patients with acute, recent, and past infections with EBV.

\begin{tabular}{|c|c|c|c|c|}
\hline \multirow{3}{*}{$\begin{array}{l}\text { Clinical diagnosis } \\
\text { (no. of subjects) }\end{array}$} & \multirow{2}{*}{\multicolumn{2}{|c|}{ Anti-VCA }} & \multirow[b]{3}{*}{ Anti-EBNA } & \multirow[t]{2}{*}{ Anti-gp250 } \\
\hline & & & & \\
\hline & $\operatorname{IgG}$ & $\operatorname{Ig} M$ & & no. negative ( $\%$ positive) \\
\hline Acute infection (26) & + & + & - & $2^{*}, 24\left(7.7^{*}\right)$ \\
\hline Recent infection (6) & + & $+1-$ & $-1+$ & $2^{*}, 4\left(33.3^{*}\right)$ \\
\hline Past infection (52) & + & - & + & $49,3(94.0)$ \\
\hline
\end{tabular}

* Only traces of antibody to gp250 were found.

formation of fingers and toes (rather plump thumbs and toes and incomplete syndactilia between the second and third toes).

Fourteen persons with histologically and serologically proven EBV-related nasopharyngeal carcinoma were also tested for antibody to gp250; all were found strongly positive.

All results are summarized in table 1.

\section{Discussion}

Eighty-four individuals with acute or past infection with EBV were examined for antibodies to the EBV membrane antigen gp250. Ninety-four percent of persons with past infection with EBV were found to be positive for antibodies to gp 250 . In $92 \%$ of all acute cases, these antibodies were completely lacking, whereas in the remaining $8 \%$ only traces were seen. Antibody to gp250 did not appear before four to six weeks after the onset of disease. Our data suggest that antibody to gp 250 is a useful marker for past infection with EBV; lack of this antibody in the presence of other markers of EBV indicates acute infection with EBV. The absence of antibody in two patients with signs of persistent, active infection with EBV and in a third case, an asymptomatic woman who gave birth to a child with hepatomegaly and slight malformations, could be a hint for a possible role of these antibodies in the prevention of endogenous reinfection and intrauterine infection. However, this has to be tested in a large number of similar cases.

Using immunofluorescence techniques, Klein et al. [1] found that antibodies to the EBV membrane antigen were present only in sera that were positive for antibody to VCA, and that they appeared de novo in patients during the acute phase of infectious mononucleosis.

Testing for EBV-neutralizing capacity is another approach to the detection of antibodies to membrane antigen as there is strong evidence that neutralizing antibodies are directed against membrane-antigen determinants [4]. Neutralizing antibodies could be detected in most human sera after infection. In one study [10], these antibodies were found in nearly all early acute-phase sera, whereas in another study [11], neutralizing antibodies were undetectable by the fifth to seventh week after the onset of infec- tious mononucleosis. These conflicting results probably were a consequence of the different methods used. Recently, Sairenji et al. [12] showed that complementindependent neutralizing antibodies were undetectable or only slightly positive in the sera of patients with acute infectious mononucleosis, but that complement-dependent neutralizing antibodies were present in these cases.

For the detection of antibody to gp250 in this study, immunoprecipitation of iodinated membrane proteins of P3HR-1 cells induced by 12-O-tetradecanoyl phorbol-13 acetate (TPA) was used in combination with SDS-PAGE and autoradiography. This technique allowed us to demonstrate antibodies to a single EBV protein in a large number of sera. The method has the advantage of high sensitivity and specificity and needs only minimal amounts of serum. An alternative approach for the demonstration of antibodies to a single membrane-antigen component (with use of an ELISA) was described recently by Luka et al. [13]. Such tests could be used for screening the large number of individuals necessary to study the function of antibody to membrane antigen and neutralizing antibodies in EBV infection. Highly sensitive tests are also an important prerequisite for a possible EBV vaccination program.

WOlFGang JILG, Hans WOLF Max von Pettenkofer Institute, University of Munich, Federal Republic of Germany

\section{References}

1. Klein G, Pearson G, Henle G, Henle W, Diehl V, Niederman JC. Relation between Epstein-Barr viral and cell membrane immunofluorescence in Burkitt tumor cells. II. Comparison of cells and sera from patients with Burkitt's lymphoma and infectious mononucleosis. J Exp Med 1968;128:1021-30

2. Gerber P, Goldstein G. Relationship of Epstein-Barr virus-induced membrane antigens in lymphoid cells to viral envelope antigens. J Immunol 1970;105:793-5.

3. Miller G, Niederman JC, Stitt DA. Infectious mononucleosis: appearance of neutralizing antibody to Epstein-Barr virus measured by inhibition of formation of lymphoblastoid cell lines. J Infect Dis 1972;125:403-6

4. Thorley-Lawson DA, Geilinger K. Monoclonal antibodies against the major glycoprotein (gp350/220) of Epstein-Barr virus neutralize infectivity. Proc Natl Acad Sci USA 1980;77:5307-11. 
5. Morgan AJ, Epstein MA, North JR. Comparative immunogenicity studies on Epstein-Barr virus membrane antigen (MA) gp340 with novel adjuvant in mice, rabbits, and cotton-top tamarins. J Med Virol 1984;13:281-92

6. Qualtiere LF, Pearson GR. Epstein-Barr virus-induced membrane antigens: immunochemical characterization of Triton X-100 solubilized viral membrane antigens from EBVsuperinfected Raji cells. Int J Cancer 1979;23:808-17

7. Bayliss GJ, Wolf $\mathbf{H}$. The regulated expression of Epstein-Barr virus. III. Proteins specified by EBV during the lytic cycle. J Gen Virol 1981;56:105-8

8. Jilg W, Hannig K. Lymphocyte surface proteins recognized by an antithymocyte-globulin. Hoppe-Seylers Z Physiol Chem 1981;362:1475-85

9. Andiman WA, Miller G. Antibody responses to Epstein-Barr Virus. In: Rose NR, Friedman H, eds. Manual of clinical immunology. 2nd ed. Washington, DC: American Society for Microbiology, 1980:628-33
10. Hewetson JF, Rocchi G, Henle W, Henle G. Neutralizing antibodies to Epstein-Barr virus in healthy populations and patients with infectious mononucleosis. J Infect Dis 1973;128:283-9

11. Chang RS. Neutralizing activity in human sera against the leukocyte-transforming agent. J Infect Dis 1973;128:50-5

12. Sairenji T, Sullivan JL, Humphreys RE. Complementdependent, Epstein-Barr Virus-neutralizing antibody appearing early in the sera of patients with infectious mononucleosis. J Infect Dis 1984;149:763-8

13. Luka J, Chase RC, Pearson GR. A sensitive enzyme-linked immunosorbent assay (ELISA) against the major EBVassociated antigens. I. Correlation between ELISA and immunofluorescence titers using purified antigens. J Immunol Methods 1984;67:145-56

THE JOURNAL OF INFECTIOUS DISEASES - VOL. 152, NO. 1 - JULY 1985

(C) 1985 by The University of Chicago. All rights reserved. 0022-1899/85/5201-0031\$01.00

\section{Dose Response of Influenza A/Washington/897/80 (H3N2) Avian-Human Reassortant Virus in Adult Volunteers}

Reassortant viruses containing the HA and neuraminidase (NA) genes of a human influenza A virus and the other six RNA segments (i.e., "internal genes") of an avian influenza virus are being developed as possible live-virus vaccine strains for use in humans [1]. Several aspects of the natural history of influenza $\mathrm{A}$ virus and the polymorphism of its genes underlie this approach to the development of a stable, attenuated reassortant influenza $A$ virus vaccine useful for humans. First, certain genes of avian influenza A viruses have been selected over a long period of time to function efficiently in cells of their natural host. The nucleotide sequence of these genes differs significantly from that of the corresponding genes of human influenza A viruses [2]. Hence, it is likely that some avian influenza viruses will replicate poorly in cells of primate respiratory

Received for publication August 13, 1984, and in revised form December 17, 1984.

This work was supported by grant no. NO1-AI-12666 from the National Institute of Allergy and Infectious Diseases.

We thank Sylvia O'Donnell and the nursing personnel of the Center for Vaccine Development for clinical and technical assistance and Linda Jordan and Marianne Guiler for their editorial assistance in the preparation of this manuscript.

Please address requests for reprints to Dr. Brian R. Murphy, Laboratory of Infectious Diseases, National Institute of Allergy and Infectious Diseases, Building 7, Room 106, National Institutes of Health, Bethesda, Maryland 20205. epithelium and thereby be attenuated. Second, one would also expect attenuated influenza A avian-human reassortant viruses that contain such genetically divergent genes to retain their attenuation phenotype following a restricted infection in man.

Ten avian influenza A viruses were initially evaluated as potential donor strains in squirrel monkeys, a primate that is susceptible to experimental infection with influenza A viruses [3]. This survey was conducted to identify avian influenza viruses that were restricted in their replication in the respiratory tract of a susceptible primate. Several avian influenza $A$ viruses that grew poorly in the upper and lower respiratory tract of squirrel monkeys were identified. One of these avian influenza viruses, the A/Mallard/6750/78 (H2N2) strain, was mated with three different human influenza $\mathrm{A}$ viruses, and avian-human influenza A reassortant viruses that possessed the $\mathrm{HA}$ and NA genes of their human influenza $A$ virus parent and the six internal genes of their avian influenza A virus parent $[1,4]$ were isolated. The avian-human influenza reassortant viruses were as restricted in the lower respiratory tract of monkeys as their avian influenza virus parent. The reassortants grew to a titer that was 1,000 times less than that of their human influenza $\mathrm{A}$ virus parent $[1,4]$. This indicated that the six internal genes of the A/Mallard/6750/78 virus reproducibly attenuated human influenza $A$ viruses for primates. One of the avian-human influenza A virus reassortants (human parent, A/Washington/80 [H3N2]) was 